\title{
INTRODUCTION TO THE SPECIAL ISSUE
}

\section{INNOVATIVE RESEARCH METHODOLOGIES WITH MIGRANT FAMILIES, CHILDREN AND YOUTH IN DIVERSE CONTEXTS}

Martha Montero-Sieburth ${ }^{1}$ and Rosa Mas GiRalt $^{2}$

Welcome to this special issue, the first one to be published fully in English by the journal Migraciones, providing open access to a selection of articles that discuss methodological and ethical aspects of person-centred and mainly qualitative research conducted with migrant families, children and/or youth in diverse contexts.

The idea behind this special issue has its origins in the ongoing discussions of the research group "Migrant families, children and youth, and their intergenerational everyday experiences and learning perspectives" that, since 2013-4², has been collaborating within IMISCOE (International Migration, Integration and Social Cohesion), the largest European network of scholars in the field of migration and integration. The present special issue has been

\footnotetext{
Amsterdam University College, M.Montero@uva.nl University of Leeds (UK), r.masgiralt@leeds.ac.uk

The research group was created in 2013-4 under the name 'The everyday experiences of youth of migrant descent in Europe, U.S. and Latin American and their integration, transnationalism and citizenship in the wake of the economic crises' and has more recently adopted the name 'Migrant families, children and youth and their intergenerational everyday experiences and learning perspectives' to be inclusive of the expanding interests and membership of the group. In 2017, this research group became a Standing Committee in IMISCOE.
} 
coordinated by Martha Montero-Sieburth, Rosa Mas Giralt and Joaquín Eguren ${ }^{4}$.

A workshop ${ }^{5}$ organised for the 12th IMISCOE Annual Conference, which took place in Geneva in June 2014, galvanised the idea of issuing an open call for papers which could expand the conversations started at the conference. The workshop, and by extension the present special issue, aimed to contribute to scholarship which, from a range of disciplinary perspectives, considers the experiences of migrants and their children within the relational context of the (transnational) family and other intergenerational contexts (Bryceson and Vuorela, 2002; Parreñas, 2005b; Parreñas, 2005a; Gardner, 2012; Haagsman and Mazzucato, 2014).

Research on the processes of incorporation of migrants and their families has traditionally developed across distinctive generational lines, focusing on migrants and their socio-economic outcomes in receiving countries such as with labour market participation, residential patterns or the schooling of their children, educational achievement and mixed marriages (Portes and Zhou, 1993; Alba and Nee, 2003; Crul and Vermeulen, 2003; Portes and DeWind, 2004).

Such research has provided important insights into cross generational trajectories of social, economic and geographic mobility and has illuminated structural dimensions of the process of incorporation. Subsequently, migrant-centred perspectives have enriched our understanding of incorporation by highlighting the potential of focusing on the migrants' everyday experiences and their dynamics for inclusion or exclusion (Ley, 2004; Conradson and Latham, 2005; Nagel and Staeheli, 2005; Ehrkamp, 2006; Eastmond, 2007; Colombo et al., 2009; Dobson, 2009; Jackson, 2014; Mas Giralt, 2015).

This latter strand of scholarship relies on person-centred research approaches which recognise children and young people as

4 The publication of this special issue has been possible thanks to the financial support of SOUNDS (South-North Dialogues on Children of Migrants) a network of scholars based at the University of Leeds (UK) which held an international conference in April 2014 and stimulated the participation of some of the authors in this special issue.

5 This workshop was entitled: 'The methodological challenges of conducting research with children of migrants (including teenagers and young adults) within (transnational) families' 
agential subjects in their own right who actively participate in family migration and incorporation processes (Bushin, 2009; Dobson, 2009). These approaches require an understanding of the challenges of accessing participant families, children and young people and ensuring that the types of methodologies used are reflective but also ethically sound.

The collaborative work and discussions of our IMISCOE research group have uncovered multiple ways in which scholars understand their role in migrant-centred processes of research and how they reflect on these processes, including the stages of change they undergo during their investigations and the forms in which they foreground the voices of migrants and their descendants. Nonetheless, given the common pressures of word-count in journal article publication, often not enough 'publication space' is available to discuss the micro-challenges and 'messiness' of developing and conducting research 'in the field'6 (Law, 2004), nor the insights that may be gained from reflecting on the conceptual, methodological and ethical decisions and approaches that well established and emerging scholars adopt in their work.

The present special issue aims to provide such a 'publication space' by offering the readers a range of articles which discuss innovative conceptual, methodological and ethical approaches in research with migrant families, children and/or young people and the types of barriers or challenges found 'in the field'. Such articles fit into the current trends which are emerging from the study of everyday experiences in the field of migration.

One caveat that we set forth is that the notion of migrant and migrant families is currently part of a major debate since the notion of immigrant does not have a universally accepted definition. Hence in this issue, we are opting to use the term migrant and migrant families instead of immigrant and immigrant families because they are conceptually used and differentiated in each of the contexts represented by our authors. While in the United States, immigrant and immigrant families may be commonplace, in Europe, the tendency is towards using migrant and migrant families as an

\footnotetext{
Gallacher and Gallagher (2008 cited in McGarry, 2016: 341) refer to messiness within the research process as 'being a disruptive force' that 'should be seen an integral element of research and can be a source of new and unexpected insight'.
} 
inclusive term. In the United States, migrant is often connoted with seasonal workers, or those in the process of moving yet not permanently settled. In Europe, variations exist from country to country and in some places, migrant is used to infer foreigner, and immigrant is use to identify refugees and asylum seekers. To avoid misunderstandings, our editorial board has opted for the use of migrant as a generic and comprehensive term.

\section{CURRENT TRENDS IN RESEARCHING MIGRANT FAMILIES, CHILDREN AND YOUTH}

Traditionally, studies on migrant families in receiving societies have followed the route of much empirical 'integration' research, mainly relying on quantitative methods to investigate the outcomes of their incorporation processes (Phillips, 2007; Schneider and Crul, 2010). This has meant that much of this empirical research 'addresses the methods, settings, subjects/objects of research' in terms of these families' processes of settlement, focusing mainly on 'the how's, when's and who's' of incorporation (cf. Alexander, 2006: 398 italics in the original).

However, in such research, which offers important insights into general patterns of settlement, the actual family everyday existence, their networks as well as the experiences of children who accompany parents are side-lined (Dobson, 2009). Whether children learn to integrate through social clubs, organizations or sports initiatives or whether parents advance in their language learning and subsequent access to benefits through the knowhow they acquire by living in specific neighbourhoods or communities is not often known. The 'whys' of how their own agency operates and whether it remains at the community level or serves to provide leverage towards social mobility remain invisible.

In addition, the rise of the transnational paradigm has challenged nationally-bounded notions of incorporation (Basch et al., 1994; Levitt, 2001) and foregrounded the 'simultaneity' which characterises migrants' experiences of 'settlement' (Levitt and Glick Schiller, 2004). This has underpinned the development of a rich scholarship on transnational families which requires the application of multi-sited and family-centred approaches 
that can capture the reconfiguration of intimate and family roles and relationships across time and space as well as the ways in which a sense of familyhood can be sustained and operationalised across borders (Bryceson and Vuorela, 2002; Chamberlain and Leydesdorff, 2004; Evergeti and Zontini, 2006; Heath et al., 2011; Haagsman and Mazzucato, 2014).

As result of these developments, migration scholars have highlighted the need to take into account how migrants themselves understand their experiences of 'integration' and transnationalism as well as their senses of affiliation and belonging to both sending and receiving societies (Ehrkamp, 2005; Walton-Roberts and Pratt, 2005; Nagel and Staeheli, 2008; Collins, 2009). In this regard, access to migrant families and their children over various generations has become both an intriguing process but also a necessary one for researchers as they shift from the objectification of the subject to understanding how we 'write culture' (Clifford and Marcus, 1986). In this shift from objectification to subjectification, the questioning of different forms of knowledge and what claims a researcher can make are becoming more commonplace (Grover, 2004; Silvey, 2004; Gallagher, 2008; Shinozaki, 2012; McGarry, 2016).

Time has become a continuum of research, both seen in longitudinal research but also in memoristic reinvention of ideas from the field. Reflexivity and self-analysis of the role of researchers has become paramount as these allow researchers to develop and explain their retrospective thinking of fieldwork (Twyman et al., 1999; Valentine, 2002; Hopkins, 2007; Shinozaki, 2012). Furthermore, media influences, social networks, photography, and literature have worked their way into the approaches that researchers today utilize to capture the lives of migrant families and youth (Thomas, 2011; Guruge et al., 2015).

Qualitative research has expanded and incorporated such approaches through multiple means. Ethnography is currently being situated within the local and structural analysis which gives rise to identifying the voices of those marginalized in societies (Kasinitz et al., 2006; Olwig, 2007; Schrooten, 2012). Ethnographies of difference, feminism, as well as critical ethnography and politics are emerging as centre-stage studies of families (Mahler and Pessar, 2006; Punch, 2012; Berg and Sigona, 2013). Not only is such research on families emanating at the local and regional levels, but also at the national and global policy level where families are viewed as subjects which 
are often 'othered' (Chamberlain, 1995; Bonjour and de Hart, 2013; Bonjour and Kraler, 2014).

Central to our understanding is how such families actually view themselves and the acculturative experiences they share. Issues which concern this growing research include whether migrant families have conflicting perspectives of settlement and 'integration', feel excluded or included, maintain group boundaries, or develop the social and cultural capital often demanded by the mainstream society they have settled into (Kennedy and MacNeela, 2014). In the final analysis, how the family adapts, changes role and functions become critical markers of the ways their children learn to negotiate their roles within neighbourhoods, communities, schools and among their peers.

Thus, current migrant family research requires that we develop knowledge about decision making processes, the role children play in families' incorporation by accessing information, peers and networks, and joining organizations (Latchem, 2014). Just as families may be products of culture, they too are producing new cultures and ways of accessing cultural capital. Such changes become evident in the ways that through globalization and transnationalism, families resort to using smartphones, blogging, internet communications to maintain their ties in multiple places (Wilding, 2006; Bacigalupe and Lambe, 2011; King-O'Riain, 2014). Their identities become less scripted and stationary and become more fluid, moving between and across cultural boundaries.

Accessing those moments of decision-making, translating, interpreting, and navigating the social systems, relating to peers and neighbours, asking questions of teachers and aides become major challenges in the field. Not only does the actual activity need to be recorded but the event and timing as well as its morphing over time also needs to be captured. An expanding range of methodological approaches and tools are becoming evident in efforts to access these 'moments', or vital conjunctures. Some of the more common techniques include the theatre of the oppressed and dance laboratories (Bello, 2011), wherein issues are acted out and understood intrinsically; storytelling (Guerrero and Tinkler, 2010), vignette writing and scenario development (Ramirez et al., 2015) as ways to weave together storylines, in-depth case-studies and hypothetical situations; blogging and web experiences (Marselis, 2013); children's drawings and depictions of self and families 
(White et al., 2010); and reflexive analysis of power dynamics and positionality of researchers (McGarry, 2016).

Over the years, there has been a return to etic and emic dimensions of anthropology (Shin, 2011); sensitivity to craft (Rosaldo, 1989); retrospective analysis; the focus on cultural objects and practices for their revelations (Hoskins, 1998); network research extending beyond the analysis of kinship structures; an expansion of visual ethnography (Pink, 2001); and an introspective interest in ethical issues impacted by social media and ICT research and the researcher's own adaptations in the field (Madge, 2007; Piacenti et al., 2014).

Such methodologies, however, raise questions about research intensity and time in the field, time and analysis post-field, and retrospection. Moreover, they also raise ethical and practical issues about what the researcher can do when participants are unwilling to participate, when children refuse to draw, or when participants, out of fear, refuse to be interviewed or participate. What secrets are kept and what is divulged matter greatly. How a researcher responds, and with what kinds of attitudes, reveals much of the internal thinking and epistemologies that drive a particular researcher's focus. Answers may not be forthcoming, and it is in that minefield of thinking, assessing, and judging one's actions, that the researcher moves forward.

It is in this rich context of methodological and ethical developments that the articles presented in this special issue invite readers to consider how to understand transnational families, children and/ or young people; how we describe and interpret their realities while not being in the midst of their everyday lives; and how we ensure that we practice ethically sound research in collaboration with these families and children. In the next section, we introduce these articles paying attention to their main contributions before ending with a few concluding remarks.

\section{OVERVIEW OF THE ARTICLES IN THE SPECIAL ISSUE}

The studies included in this special issue provide a range of insights into research conducted with migrant families, children and/ or young people, including issues arising from methodological and 
conceptual approaches as well as the intersection between methods, researchers' positionality and ethical praxis. The contributors come from different disciplines (e.g. sociology, education, geography), are at different stages of their careers - from early career to well established scholars - and their work covers different geographical areas and migrant groups, mainly in the minority world but with an important contribution from the majority world. Together, they provide a cross-disciplinary journey through methodological considerations, reflexivity and researchers' positionality, power relations between researcher and participants (adults and children), and relational ethical practices which fully recognise participants as co-producers of knowledge.

The two first articles adopt mainly a methodological lens, proposing innovative conceptual considerations to understandings of transnational families' social mobility and sports policies addressed to young people of migrant descent. To start with, Oso and Grimalt invite us to consider the social mobility strategies of transnational families by drawing from a qualitative, multi-sited and longitudinal project carried out in Spain and in Ecuador. These authors analyse the ways in which households negotiate transnational social mobility strategies taking into account the role that each individual holds within the family unit (fathers, mothers, elder children, younger children and grandparents) - intergenerational dimension - and in relation to the migration process (migrating as pioneers, staying behind, etc.) - transnational space. Thusly, they assess the actions that transnational households undertake as a whole, over time and space, in order to move up the social ladder. Their work foregrounds both the relevance of fully acknowledging the relational lives of migrants as well as the role of family members left behind as agents of social mobility strategies within transnational space.

Next, García Arjona's article, moves our attention to the sports policies for the 'integration' of young people of migrant descent that have become increasingly common in Western countries. In contrast to the more prolific scholarship which has focused on grassroots migrant perspectives on these types of sports initiatives, García Arjona advocates for a political discourse analysis of sports as a field of 'integration'. In doing so, she identifies the types of methodological challenges that can arise when choosing to study this field from a political sociological comparative perspective. She uses material from such a project conducted in Paris and 
Madrid to illustrate the contested conceptualizations of the young people who are targeted by these policies as well as the challenges of devising comparative selection criteria for different levels of institutional actors involved in designing or implementing these policies in different geographical and political contexts. Her work helps us to interrogate the ideological constructs of sports as a field of 'integration' and to consider the practical implications that such constructs (as potential devices for cultural and social recognition or marginalisation) may have on the inclusion/ exclusion dynamics that young people of migrant descent face in their everyday lives.

The special issue then proceeds to engage with themes of researcher positionality, power relations and reflexivity. Draghici revisits an intercultural project she conducted in 2013 with Roma migrant children and their families while being a volunteer with a charity association providing educational and other types of support for this group in the slums of Paris. She adopts the use of a reflexive retrospective analysis to interrogate her perspectives, experiences and positionality. 'By looking back', she is able to bring added value to her initial findings and to intercultural research more widely. This approach also provides an opportunity to fully appreciate the shortcomings and strengths of completed fieldwork, consolidate skills for future research and more fully appreciate the learning derived from the participants, both adults and children. It is actually this acknowledgement of the learning that researchers derive from the participants and how to fully recognise their role as co-producers of knowledge that leads us to the next step of the journey in this special issue.

In his contribution, Lind explores the potential of ethics-asprocess as a tool to co-produce knowledge through the ethical discussions which take place between researchers and gatekeepers or participants during research. Based on a comparative ethnographic study conducted in Birmingham (UK) and Malmö (Sweden) with families fearing deportation, he considers his own ambivalent positionality as an activist and researcher. This ambivalence foregrounds the ethics-as-process approach (and method) and underpins the author's reflections on how he addressed ethical dilemmas in the field, providing particular examples of how ethical deliberations became opportunities to co-produce knowledge with the gatekeepers or participating parents and children. Lind's work in 
the sensitive field of deportability raises important questions about the positionality of researchers in relation to the highly politicised area of migration and the necessary considerations which scholars (particularly activist-scholars) need to engage with when reflecting on the impact of their work on and for the migrant families, children and young people who take part in their research as well as for wider dynamics of social justice. The next and final article in this special issue proposes an approach that can help to develop ethically sound research which creates productive knowledge with and for the participants.

Ball and Beazley provide an insightful and necessary contribution by bringing to the fore perspectives from research conducted with transnational families and children in the Global South. Drawing from research on birth registration decision making by migrant parents in Indonesia, these authors problematize dominant minority world's ethical research praxis and advocate for an approach centred on the relational ethics of cultural safety, rights and desire in communityengaged research. Such an approach can lead to research practices with migrant communities that respect their cultures and traditions, provide psychosocial and cultural safety for participants and do not disrupt or erode the wider community connections while producing fruitful and participant led data. Their paper reminds us of the need to continue to expand upon South-North dialogues which can guarantee the well-being and rights of research participants, promote co-production of knowledge and broaden our research gaze, providing more pluralistic and respectful understanding of the experiences of migrant families, children and youth.

\section{CONCLUDING REMARKS}

In concluding, this special issue has attempted to demonstrate how methodological innovations are taking place in the field of migration and in particular with migrant and transnational families. These innovations fit into the current trends already mentioned, but they also provide a context for the changes which have ensued in migration studies. In essence, the articles argue for considering the positionality of the researcher, developing a strong commitment to migrant advocacy, questioning the interplay of migrants' social 
lives with their own integration and social mobility, and capturing the inner thinking of families in "how they are making it" in their diverse settings.

Among the methodological attributes worth highlighting from this special issue are the scholars' ability to use more than one language when researching; to carry out comparative research; to present their research as junior and seasoned scholars; to make clear the positionality of their own perspectives, their self-criticism and retrospection; to identify clearly their roles within relationships of power; and to advance the discussion of the types of ethics that need to be present in research with families and children in their everyday contexts.

The ability of some of these researchers to cross over linguistic boundaries (e.g. French-Romanian, Spanish-French, and English) attests to the strength of cross-linguistic research. When researchers are expected to use the language of the country to which families have migrated, but can also rely on using their first language (or interpreters) to address specific needs of participant families, shows not only the researchers' adaptability, but also their sensitivity to understanding these families' needs and culture. Some of the articles make this apparent in the way the authors conducted their studies at the local level in neighbourhoods, in particular communities (or sports groups) or across cities.

Such cross-linguistic practice also extends to the examples of comparative research present in the special issue; as scholars situate families in one context and compare and contrast their perspectives with similar families in another context, using deportability or adaptability as their units of analysis. The comparisons presented yield not only local or national analysis but allow for different methodological formats to be used which are innovative, inventive and experimental.

Described in these articles are also the multiple approaches that researchers used to access families and youth and which included visual, didactic, digital and social media tools and means. Single approaches or the use of mixed methods are apparent by the descriptions scholars make of their multi-layered and multi-faceted innovations. In some cases, the more traditional ethnographic approach of taking photographs became adapted to the demands of the field and in other cases the data demanded use of less traditional forms as, for instance, in developing an advocacy narrative. 
Furthermore, the inclusion in the special issue of junior researchers' perspectives alongside seasoned scholars showcases different disciplinary trajectories, training, and theoretical perspectives, ranging from political analysis to ethnographic research in situ. In sharing reflective and retrospective lenses, these scholars compel the reader to consider the role and position of researchers as instruments of research. Not only were the researchers in these studies concerned with providing a safe, neutral space where their participants could voluntarily engage, but also a space that was not infringed upon. They vocalize the need to see themselves as conduits for participants, who having their own voice, need to make their recorded thoughts and processes evident. Through the researcher's pen and display of sensitive analysis, the lives of their participants are communicated.

Notable in a few of the articles is the need for auto-criticism and reflection, which emerges prior to, while in the field and after fieldwork has been completed. The questioning of what went well, what went wrong, and whether the everyday experiences were understood are some of the issues addressed. Stemming back to Burawoy's (2003) reflexive ethnography, several of the authors attend to the meaning of looking back and what this entails, identifying their roles within relationships of power and advancing the discussion of the types of ethics that need to be present "in the field" with families and children in their everyday contexts.

Needless to say, the understanding of power relationships between researchers and their participants become palpable in many of the articles. The role of researchers, given their academic standing, may be intimidating to families; how the relationships of power are played out in the research process is what affords an 'equal playing field' of research and provides social and cultural safety for participants. At times, as is shown in the articles, the researcher needs to leave their role aside and act on behalf of the families' needs.

Several of the authors indicate the importance of this responsibility when working with children or when designing research which demands children do tasks they are not familiar with or simply are not interested in doing. How to collaborate, and on what basis, are critical issues raised by some of the scholars of this issue, who strongly advocate for the co-construction of knowledge. Having taken the knowledge from the field and reflected on their participants' contributions, some of the articles show the process of 
constructing new categories and themes in collaboration with the participants. Thus, the production of knowledge becomes a shared endeavour. Finally, these scholars also identify the agency found in the on-going activities of families and their decision-making processes, as well as in the negotiation strategies of youth and their experiences in the communities where they live.

The research and innovative methodologies these scholars advance are signposts to the types of challenges and issues that will need to be overcome in migration research. In representing migrant families and children in their everyday lives, they offer invaluable insights that capture such a reality and afford the field innovative methodologies.

\section{REFERENCES}

Alba, R. \& NeE, V. (2003): Remaking the American Mainstream: Assimilation and Contemporary Immigration. Cambridge, MA, Harvard University Press.

AleXANDeR, C. (2006): «Introduction: Mapping the issues». Ethnic and Racial Studies, 29, 397-410.

Bacigalupe, G. \& Lambe, S. (2011): «Virtualizing Intimacy: Information Communication Technologies and Transnational Families in Therapy». Family Process, 50, 12-26.

Basch, L., Glick Schiller, N. \& Blanc, C. S. (1994): Nations Unbound: Transnational Projects, Postcolonial Predicaments, and Deterritorialized NationStates. Amsterdam, Gordon and Breach.

BelLo, B. G. (2011): «Empowerment of young migrants in Italy through nonformal education: putting equality into practice». Journal of Modern Italian Studies, 16, 348-359.

Berg, M. L. \& SigONA, N. (2013): «Ethnography, diversity and urban space». Identities, 20, 347-360.

Bonjour, S. \& De Hart, B. (2013): «A proper wife, a proper marriage: Constructions of 'us' and 'them' in Dutch family migration policy». European Journal of Women's Studies, 20, 61-76.

Bonjour, S. \& Kraler, A. (2014): «Introduction: Family Migration as an Integration Issue? Policy Perspectives and Academic Insights». Journal of Family Issues, 36, 1407-1432.

Bryceson, D. \& Vuorela, U. (2002): The Transnational Family: New European Frontiers and Global Networks. Oxford; New York, Berg.

Burawoy, M. (2003): «Revisits: An Outline of a Theory of Reflexive Ethnography». American Sociological Review, 68, 645-679. 
Bushin, N. (2009): «Researching family migration decision-making: a children-in-families approach». Population, Space and Place, 15, 429-443.

Chamberlain, M. (1995): «Family narratives and migration dynamics: Barbadians to Britain». Immigrants \& Minorities, 14, 153-169.

Chamberlain, M. \& LeydesdorfF, S. (2004): «Transnational Families: Memories and Narratives». Global Networks, 4, 227-241.

Clifford, J. \& Marcus, G. E. (eds.) (1986): Writing culture: the poetics and politics of ethnography: a School of American Research advanced seminar. Berkeley; London: University of California Press.

Collins, F. L. (2009): «Transnationalism unbound: detailing new subjects, registers and spatialities of cross-border lives». Geography Compass, 3, 434-458.

Colombo, E., Leonini, L. \& Rebughini, P. (2009): «Different but not stranger: everyday collective identifications among adolescent children of immigrants in Italy». Journal of Ethnic and Migration Studies, 35, 37-59.

Conradson, D. \& Latham, A. (2005): «Transnational urbanism: attending to everyday practices and mobilities». Journal of Ethnic and Migration Studies, 31, 227-233.

Crul, M. \& Vermeulen, H. (2003): «The Second Generation in Europe». International Migration Review, 37, 965-986.

Dobson, M. E. (2009): «Unpacking children in migration research». Children's Geographies, 7, 355-360.

EAstmond, M. (2007): «Stories as Lived Experience: Narratives in Forced Migration Research». Journal of Refugee Studies, 20, 248-264.

EhrкAmp, P. (2005): «Placing identities: transnational practices and local attachments of Turkish Immigrants in Germany». Journal of Ethnic and Migration Studies, 31, 345-364.

EhrKamp P. (2006): «"We Turks are no Germans": assimilation discourses and the dialectical construction of identities in Germany». Environment and Planning A, 38, 1673-1692.

Evergeti, V. \& Zontini, E. (2006): «Introduction: Some critical reflections on social capital, migration and transnational families». Ethnic and Racial Studies, 29, 1025-1039.

Gallagher, M. (2008): “Power is not an evil”: rethinking power in participatory methods». Children's Geographies, 6, 137-150.

GARDNER, K. (2012): "Transnational Migration and the Study of Children: An Introduction». Journal of Ethnic and Migration Studies, 38, 889-912.

Grover, S. (2004): "Why won't they listen to us?: on giving power and voice to children participating in social research». Childhood, 11, 81-93.

Guerrero, A. L. \& Tinkler, T. (2010): Refugee and Displaced Youth Negotiating Imagined and Lived Identities in a Photography-Based Educational Project in the United States and Colombia. Anthropology \& Education Quarterly, 41, 55-74.

Guruge, S., Hynie, M., Shakya, Y., Akbari, A., Htoo, S. \& Abiyo, S. (2015): Refugee Youth and Migration: Using Arts-Informed Research to Understand Changes in Their Roles and Responsibilities. 2015, 16. 
Haagsman, K. \& Mazzucato, V. (2014): «The Quality of Parent-Child Relationships in Transnational Families: Angolan and Nigerian Migrant Parents in The Netherlands". Journal of Ethnic and Migration Studies, 40, 1677-1696.

Heath, S., McGhee, D. \& Trevena, P. (2011): «Lost in Transnationalism: Unraveling the Conceptualisation of Families and Personal Life Through a Transnational Gaze». Sociological Research Online, 16, 12.

Hopkins, P. 2007. «Positionalities and knowledge: negotiating ethics in practice». ACME: An International E-Journal for Critical Geographies [Online], 6. Available: http://www.acme-journal.org/Volume6-3.htm [Accessed 11/12/2010].

Hoskins, J. (1998): Biographical objects: how things tell the stories of people's lives. New York; London, Routledge.

JACKson, L. (2014): «The Multiple Voices of Belonging: Migrant Identities and Community Practice in South Wales». Environment and Planning A, 46, 1666-1681.

Kasinitz, P., Mollenkopf, J. H. \& Waters, M. C. (eds.) (2006): Becoming New Yorkers: ethnographies of the second generation. New York: Russell Sage Foundation.

Kennedy, L. A. \& Macneela, P. (2014): «Adolescent acculturation experiences: A meta-ethnography of qualitative research». International Journal of Intercultural Relations, 40, 126-140.

King-O'RiaIN, R. C. (2014): "Emotional streaming and transconnectivity: Skype and emotion practices in transnational families in Ireland». Global Networks, 15, 256-273.

Latchem, J. (2014): «Researching families and relationships: reflections on process». International Journal of Social Research Methodology, 17, 90-92.

Law, J. (2004): After method: mess in social science research. London, Routledge.

LEVITT, P. (2001): «Transnational migration: taking stock and future directions». Global Networks, 1, 195-216.

Levitt, P. \& Glick Schiller, N. (2004): «Conceptualizing simultaneity: a transnational social field perspective on society». International Migration Review, 38, 1002-1039.

LEY, D. (2004): "Transnational spaces and everyday lives». Transactions of the Institute of British Geographers, New Series, 29, 151-164.

MAdGE, C. (2007): «Developing a geographers' agenda for online research ethics». Progress in Human Geography, 31, 654-674.

Mahler, S. J. \& Pessar, P. R. (2006): «Gender Matters: Ethnographers Bring Gender from the Periphery toward the Core of Migration Studies». International Migration Review, 40, 27-63.

Marselis, R. (2013): "Migrant life stories and the Web: the experience of having your life story made public». Social Semiotics, 23, 368-384.

MAS GIRALT, R. (2015): «Socio-cultural invisibility and belonging: Latin American migrants in the north of England». Emotion, Space and Society, 15, 3-10. 
McGARRY, O. (2016): «Repositioning the research encounter: exploring power dynamics and positionality in youth research». International Journal of Social Research Methodology, 19, 339-354.

Nagel, C. R. \& Staeheli, L. A. (2005): "We're just like the Irish": narratives of assimiliation, belonging and citizenship amongst Arab-American activists». Citizenship Studies, 9, 485-498.

Nagel, C. R. \& Staeheli, L. A. (2008): "Integration and the negotiation of 'here' and 'there': the case of British Arab activists». Social \& Cultural Geography, 9, 415-430.

Olwig, K. F. (2007): Caribbean journeys:an ethnography of migration and home in three family networks. Duke University Press.

PARREÑAs, R. (2005a): Children of Global Migration: transnational families and gendered woes. Stanford, Stanford University Press.

PARREÑAs, R. (2005b): «Long distance intimacy: class, gender and intergenerational relations between mothers and children in Filipino transnational families». Global Networks, 5, 317-336.

Phillips, D. (2007): «Ethnic and racial segregation: a critical perspective». Geography Compass, 1, 1138-1159.

Piacenti, D. J., Rivas, L. B. \& Garrett, J. (2014): «Facebook Ethnography: The Poststructural Ontology of Transnational (Im) Migration Research». International Journal of Qualitative Methods, 13, 224-236.

PInK, S. (2001): Doing visual ethnography. London, Sage.

Portes, A. \& Dewind, J. (2004): «A Cross-Atlantic dialogue: the progress of research and theory in the study of international migration». International Migration Review, 38, 828-851.

Portes, A. \& Zhou, M. (1993): «The new second generation: segmented assimilation and its variants». Annals of the American Academy of Political and Social Science, 530, 74-96.

Punch, S. (2012): «Studying Transnational Children: A Multi-Sited, Longitudinal, Ethnographic Approach». Journal of Ethnic and Migration Studies, 38, 1007-1023.

Ramirez, R., Mukherjee, M., Vezzoli, S. \& Kramer, A. M. (2015): "Scenarios as a scholarly methodology to produce "interesting research"». Futures, $71,70-87$.

RosALDo, R. (1989): Culture and truth: the remaking of social analysis. Boston, Beacon.

SCHNEIDER, J. \& CRUL, M. (2010): «New insights into assimilation and integration theory: introduction to the special issue». Ethnic and Racial Studies, 33, 1143-1148.

Schrooten, M. (2012): «Moving ethnography online: researching Brazilian migrants' online togetherness». Ethnic and Racial Studies, 35, 1794-1809.

SHIN, R. (2011): "Social Justice and Informal Learning: Breaking the Social Comfort Zone and Facilitating Positive Ethnic Interaction». Studies in Art Education, 53, 71-87. 
SHINOZAKI, K. (2012): «Transnational dynamics in researching migrants: selfreflexivity and boundary-drawing in fieldwork». Ethnic and Racial Studies, 35, 1810-1827.

Silvey, R. (2004): "Power, difference and mobility: feminist advances in migration studies». Progress in Human Geography, 28, 490-506.

Thomas, D. (2011): «The Global Mediterranean: Literature and Migration». Yale French Studies, 120, 140-153.

Twyman, C., Morrison, J. \& Sporton, D. (1999): «The final fifth: autobiography, reflexivity and interpretation in cross-cultural research». Area, 31, 313-325.

VALENTINE, G. (2002): «People like us: negotiating sameness and difference in the research process». In: MOSS, P. (ed.) Feminist geography in practice: research and methods. Oxford; Malden (US): Blackwell.

Walton-Roberts, M. \& Pratt, G. (2005): «Mobile modernities: a South-Asian family negotiates immigration, gender and class in Canada». Gender, Place and Culture, 12, 173-195.

White, A., Bushin, N., Carpena-Méndez, F. \& Ní Laoire, C. (2010): «Using visual methodologies to explore contemporary Irish childhoods». Qualitative Research, 10, 143-158.

Wilding, R. (2006): “Virtual” intimacies? Families communicating across transnational contexts». Global Networks, 6, 125-142. 
